\title{
Geographical and socioeconomic variation in the prevalence of asthma symptoms in English and Scottish children
}

\author{
E Duran-Tauleria, R J Rona
}

\begin{abstract}
Background-There has been controversy over the relation between poverty and asthma in the community. The aim of this analysis was to disentangle geographical and socioeconomic variation in asthma symptoms.

Methods-The analysis is based on parental reports of symptoms from data collected in 1990 and 1991. Children aged 5-11 years from three populations (English representative sample, Scottish representative sample, and an English inner city sample) were included. Of 17677 eligible children, between 14490 (82.0\%) and $15562(88.0 \%)$ children were available for analysis according to symptom group. Results-Wheezy symptoms were less prevalent in the Scottish sample than in the English samples and asthma attacks were most prevalent in the English representative sample. Asthma attacks were less prevalent in inner city areas than in the English representative sample (OR $0.79,95 \%$ CI 0.66 to 0.95 ), but persistent wheeze and other respiratory symptoms were more prevalent (OR 1.95, 95\% CI 1.65 to 2.32 and OR $1.67,95 \%$ CI 1.52 to 1.84 , respectively). The prevalence of persistent wheeze was higher in children whose father's social class was low and in those living in areas with a high Townsend score (an index of poverty) than in other children $(p<0.001)$. Of the 14 areas with the highest Townsend score, 13 had an OR above 1 and six had an OR significantly higher than the reference area.

Conclusions-Persistent wheeze is more prevalent in poor areas than in less deprived areas. This may indicate that poverty is associated with severe asthma or that a high percentage of persistent asthma symptoms in inner city areas are unrecognised and untreated.

(Thorax 1999;54:476-481)
\end{abstract}

Keywords: asthma; wheeze; socioeconomic variation; geographical variation; children

Asthma mortality and hospital admissions for asthma are not evenly distributed. ${ }^{1-7}$ Asthma mortality is higher in the poor, in Hispanics and black subjects in the USA, ${ }^{2}$ and in Britain in those in social classes IV and V or without access to a car, ${ }^{4}$ albeit not in all studies. ${ }^{8}$ Admissions to hospital for asthma are more frequent in the poor ${ }^{2}$ and in minority groups. ${ }^{1279}$ However, the association between asthma in the population and socioeconomic status, although assessed in many studies, has provided contradictory information. ${ }^{10}$ Studies have shown that the prevalence of asthma is not consistently related to socioeconomic status, but a few studies have shown that severe asthma may be more frequent in the poorer groups of society..$^{11}$

The studies on asthma morbidity and socioeconomic gradients have not examined geographical variation in the population. Regional variation of asthma in Britain has been studied, but the analysis did not include a concurrent assessment of socioeconomic factors. ${ }^{12}{ }^{13}$ Assessing the impact of social disadvantage on disease by analysing regional variation is insensitive because of the varying socioeconomic circumstances of individuals within this unit of analysis. In the National Study of Health and Growth (NSHG) we collected data on primary school children from 56 study areas in England and Scotland, including information on asthma symptoms and socioeconomic variables. The schools from each area corresponded to a small catchment population and would be expected to have less socioeconomic variation than in a large geographical area. In this analysis we examined the geographical variation of asthma and other symptoms of asthma between study areas, with and without adjustment for other socioeconomic variables. This approach enables assessment of whether any observed geographical variation of asthma in Britain might be explained by socioeconomic status.

\section{Methods}

The NSHG was an annual survey of 5-11 year old children. It included three samples - an English sample (22 areas) and a Scottish sample (14 areas), both based on stratified random sampling of employment exchange areas with proportionally more from poorer social groups, ${ }^{14}$ and an English inner city sample (20 areas). As the distribution of social class in the 
Table 1 Prevalence of respiratory symptoms by sample

\begin{tabular}{|c|c|c|c|c|c|c|c|c|c|}
\hline & \multicolumn{2}{|c|}{$\begin{array}{l}\text { All three samples } \\
(N=17677)\end{array}$} & \multicolumn{2}{|c|}{$\begin{array}{l}\text { English representative } \\
(N=6463)\end{array}$} & \multicolumn{2}{|c|}{$\begin{array}{l}\text { Scottish representative } \\
(N=4165)\end{array}$} & \multicolumn{2}{|c|}{$\begin{array}{l}\text { English inner city } \\
(N=7049)\end{array}$} & \multirow[b]{2}{*}{$p$ value ${ }^{\star}$} \\
\hline & $n / N$ & $\%$ & $n / N$ & $\%$ & $n / N$ & $\%$ & $n / N$ & $\%$ & \\
\hline Asthma attacks & $1028 / 15489$ & 6.6 & $433 / 5934$ & 7.3 & $254 / 4016$ & 6.3 & $341 / 5539$ & 6.2 & 0.032 \\
\hline Bronchitis attacks & $356 / 15113$ & 2.4 & $153 / 5816$ & 2.6 & $55 / 3932$ & 1.4 & $148 / 5385$ & 2.7 & 0.001 \\
\hline Occasional wheeze & $2196 / 15562$ & 14.1 & $879 / 5958$ & 14.8 & $537 / 4018$ & 13.4 & $780 / 5586$ & 14.0 & 0.137 \\
\hline Persistent wheeze & $728 / 15495$ & 4.7 & $215 / 5937$ & 3.6 & $133 / 4002$ & 3.3 & $380 / 5586$ & 6.8 & 0.001 \\
\hline Cough first thing in the morning & $1047 / 15436$ & 6.8 & $336 / 5909$ & 5.7 & $204 / 3998$ & 5.1 & $507 / 5529$ & 9.2 & 0.001 \\
\hline Cough other times & $2521 / 15375$ & 16.4 & $830 / 5871$ & 14.1 & $498 / 3997$ & 12.5 & $1193 / 4314$ & 21.7 & 0.001 \\
\hline Cold goes to chest & $4043 / 15553$ & 26.0 & $1462 / 5965$ & 24.5 & $982 / 4024$ & 24.4 & $1599 / 5564$ & 28.7 & 0.001 \\
\hline
\end{tabular}

^Testing for differences between samples for each symptom.

English and Scottish samples was similar to that in the general population, ${ }^{15}$ we refer to them as representative samples in this paper. The English inner city sample was selected according to characteristics of deprivation and proportion of ethnic minority groups. ${ }^{16}$ Data collected in the 1990 and 1991 surveys were included in the analysis.

Information on respiratory illness in the children and their parents and on family background was obtained from a questionnaire completed by a parent. Questionnaires were distributed by postal or satchel delivery and parents were contacted up to three times to maximise response rate. Parents reported whether the child had had asthma or bronchitis in the last 12 months, whether he or she usually coughed first thing in the morning or coughed at any other time, whether his or her chest ever sounded wheezy or whistling and, if so, whether these symptoms were present on most days or nights. Children whose parents answered "yes" to both questions on wheeze are described as having persistent wheeze and those whose parents answered "yes" only to the first question are referred to as having occasional wheeze. We did not ask whether any respiratory conditions were diagnosed by a doctor. In the inner city sample ethnic groups were classified as white, Afro-Caribbean, children originating from the Indian subcontinent, and others (a heterogeneous group) to which the English and Scottish representative samples were added separately. From the 1991 census the proportion of unemployed, the proportion of those without a car, overcrowding, and the proportion aged over 65 years were obtained for each study area defined by the

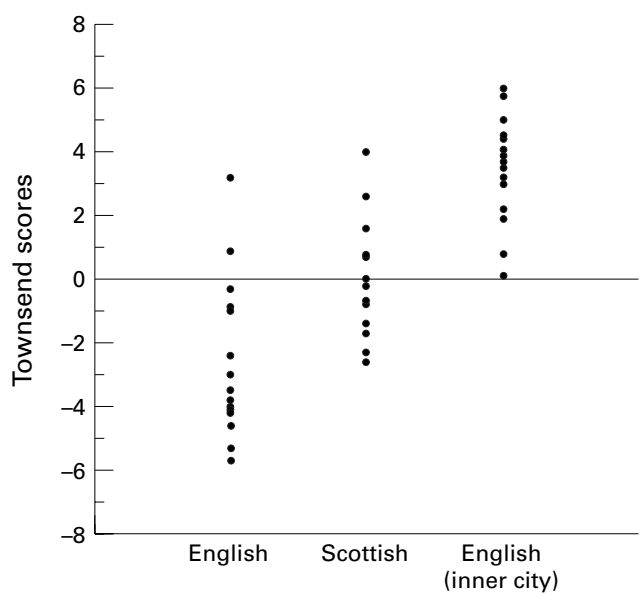

Figure 1 Variation in Townsend scores by sample. school postcode at sector level. Based on these four items of information the Townsend deprivation score of each area was calculated. ${ }^{17}$

The main analysis was carried out for four groups of symptoms: occasional wheeze; persistent wheeze; asthma attacks; and any respiratory symptoms excluding wheeze or asthma attacks. In addition, when assessing the distribution of symptoms according to sample a further analysis was carried out for children with either asthma or persistent wheeze. Multiple logistic regression analyses were carried out for each group of symptoms between areas unadjusted and, if statistically significant $(\mathrm{p}<0.05)$ variation was demonstrated, adjusted for the following possible explanatory factors: age as a continuous variable, sex, number of children in the family, parents' atopic conditions, father's social class, maternal smoking at home, and the Townsend deprivation score of the area of residence. We excluded from the analyses as few children as possible. For each of the independent variables except continuous variables we added a not known category. Children whose parents did not provide information for a respiratory symptom were excluded from that analysis only. Thus, there are small differences in the number of participants according to the respiratory symptom analysed. As the logistic regression assumes independent observations, we repeated the analysis using generalised estimating equations (GEE) to assess whether the estimates changed when correlation between children within areas was taken into account. There were no major differences between the two analyses, except that the analysis using GEE had slightly wider $95 \%$ confidence intervals. The results are presented as prevalences and odds ratios (OR) with their 95\% confidence intervals.

\section{Results}

The sample comprised 17677 children, some of whom were excluded because they did not have information on respiratory illness in the main analysis. The number of children in the analysis is shown in table 1 . The response rate varied from $85.5 \%$ for bronchitis attacks to $88 \%$ for occasional wheeze. Persistent wheeze and cough and colds going to the chest were significantly more prevalent in the English inner city sample than in the other two samples $(p<0.001)$, asthma attacks were slightly more frequent in the English representative sample than in the other two samples $(p=0.032)$, and bronchitis attacks were less frequent in Scotland than in the other two samples $(\mathrm{p}<0.001)$. 
Table 2 Prevalences and odds ratios (OR) by respiratory symptom group and sample*

\begin{tabular}{|c|c|c|c|c|c|c|c|c|c|c|}
\hline \multirow[b]{2}{*}{ Sample } & \multicolumn{2}{|c|}{$\begin{array}{l}\text { Other respiratory } \\
\text { symptoms }(N=14490)\end{array}$} & \multicolumn{2}{|c|}{$\begin{array}{l}\text { Occasional wheeze } \\
(N=15562)\end{array}$} & \multicolumn{2}{|c|}{$\begin{array}{l}\text { Persistent wheeze } \\
(N=15495)\end{array}$} & \multicolumn{2}{|c|}{$\begin{array}{l}\text { Asthma attacks } \\
(N=15489)\end{array}$} & \multicolumn{2}{|c|}{$\begin{array}{l}\text { Asthma or persistent } \\
\text { wheeze }(N=14490)\end{array}$} \\
\hline & $\%$ & $O R(95 \% C I)$ & $(\%)$ & $O R(95 \% C I)$ & $(\%)$ & $O R(95 \% C I)$ & $(\%)$ & OR $(95 \% C I)$ & $(\%)$ & $O R(95 \% C I)$ \\
\hline English representative & 16.7 & 1.00 & 14.7 & 1.00 & 3.6 & 1.00 & 7.3 & 1.00 & 6.8 & 1.00 \\
\hline Scottish representative & 16.8 & $1.01(0.90$ to 1.13$)$ & 13.4 & $0.89(0.79$ to 1.00$)$ & 3.3 & $0.91(0.73$ to 1.14$)$ & 6.3 & 0.73 (0.60 to 0.90$)$ & 5.4 & 0.78 (0.66 to 0.93$)$ \\
\hline Inner city & 25.1 & $1.67(1.52$ to 1.84$)$ & 13.9 & $0.93(0.84$ to 1.04$)$ & 6.8 & $1.95(1.65$ to 2.32$)$ & 6.2 & $0.79(0.66$ to 0.95$)$ & 7.8 & $1.15(0.99$ to 1.33$)$ \\
\hline Total & 19.7 & & 14.1 & & 4.7 & & 6.6 & & 6.8 & \\
\hline
\end{tabular}

$\star$ Adjusted for age and sex.

The Townsend scores between the three samples were markedly different (fig 1). All areas in the English inner city sample had a positive score and most had a score of 3 or more, denoting a high level of deprivation. Most scores were negative in the English sample while the scores of the areas in the Scottish sample were between the English representative sample, and the English inner city area. Table 2 shows the prevalence and OR for the respiratory symptom groups by sample, adjusted only for age and sex. Children in inner city areas had a higher OR for persistent wheeze and "other respiratory symptoms". The OR for persistent wheeze in the inner city sample is almost double that of the other two samples. Asthma attacks were more prevalent in the representative English sample than in the other two samples. The difference in OR of asthma attacks and persistent wheeze was not statistically significant between the English sample and the inner city sample. The prevalence of symptoms in the Scottish sample was lower or similar to that of the English sample.

Table 3 shows the prevalence and OR for persistent wheeze, unadjusted and adjusted according to sample, social class, or Townsend score. The adjusted models were also adjusted for family size, parental atopy, and maternal smoking at home. In each model we repeated the analyses to assess the OR by ethnic group separately. There was a marked gradient in the OR for persistent wheeze by social class and the Townsend score ( $\mathrm{p}$ for trend <0.001). Adjustment for social class did not markedly modify the OR differences between samples shown in the unadjusted model, while adjustment for the Townsend score of each area eliminated the differences in OR between the inner city sample and the English sample and the OR in the Scottish sample decreased markedly. In the analyses according to ethnicity there was clear evidence that the high OR in the inner city sample was consistent in all ethnic groups as a statistically significant OR for persistent wheeze compared with the English representative sample shown in the unadjusted model. Adjustment for the Townsend score eliminated the differences in OR between the ethnic groups.

The distribution of asthma attacks was homogeneous between areas and none was significantly different from the comparison area (chosen because its prevalence was nearest to the prevalence of the grand total) (fig 2). There were very few areas that were significantly different from the comparison group and they were unrelated to the Townsend score distribution. The same was observed for occasional wheeze (not shown). Figure 3 shows a marked association between the prevalence of persistent wheeze by area and the Townsend score distribution by quartiles adjusted for all the other independent variables in the model. In the upper quartile of the Townsend distribution (poorest areas) all the areas have a high OR and six areas had an OR significantly different

Table 3 Prevalence of persistent wheeze and odds ratios (with 95\% confidence intervals) unadjusted or adjusted either for father's social class or the Townsend scoret

\begin{tabular}{|c|c|c|c|c|c|}
\hline & $N$ & $\%$ & Unadjusted & $\begin{array}{l}\text { Model includes } \\
\text { social classt }\end{array}$ & $\begin{array}{l}\text { Model includes } \\
\text { Townsend scoret }\end{array}$ \\
\hline \multicolumn{6}{|l|}{ Sample } \\
\hline English & 5937 & 3.6 & 1 & 1 & 1 \\
\hline Scottish & 4002 & 3.3 & $0.91(0.64$ to 1.26$)$ & $0.90(0.68$ to 1.19$)$ & $0.60(0.46$ to 0.79$)$ \\
\hline Inner city & 5556 & 6.8 & $1.94(1.44$ to 2.61$)$ & $1.70(1.33$ to 2.17$)$ & $0.99(0.73$ to 1.35$)$ \\
\hline \multicolumn{6}{|l|}{ Townsend score } \\
\hline$<-3.25$ & 4380 & 2.8 & 1 & - & 1 \\
\hline-3.25 to -0.10 & 4298 & 3.5 & $1.29(0.89$ to 1.86$)$ & - & $1.69(1.15$ to 2.48$)$ \\
\hline-0.00 to 3.35 & 3394 & 5.9 & $2.18(1.52$ to 3.14$)$ & - & $2.50(1.78$ to 3.51$)$ \\
\hline$>3.35$ & 3423 & 7.3 & $2.77(2.02$ to 3.79$)$ & - & $2.77(1.80$ to 4.26$)$ \\
\hline \multicolumn{6}{|l|}{ Social class } \\
\hline I, II, IIIN & 3942 & 2.3 & 1 & 1 & - \\
\hline IIIM & 4566 & 3.9 & $1.79(1.21$ to 1.96$)$ & 1.54 (1.19 to 1.98$)$ & - \\
\hline IV, V & 2386 & 5.7 & $2.06(1.53$ to 2.77$)$ & $1.89(1.40$ to 2.16$)$ & - \\
\hline Not known & 4601 & 7.0 & $2.47(1.85$ to 3.29$)$ & $2.16(1.61$ to 2.99$)$ & - \\
\hline \multicolumn{6}{|l|}{ Ethnic group ${ }^{\star}$} \\
\hline English & 5937 & 3.6 & 1 & 1 & 1 \\
\hline Scottish & 4002 & 3.3 & $0.90(0.64$ to 1.26$)$ & $0.90(0.68$ to 1.19$)$ & $0.60(0.45$ to 0.79$)$ \\
\hline \multicolumn{6}{|l|}{ Inner city: } \\
\hline White & 1827 & 8.4 & $2.24(1.54$ to 3.27$)$ & $1.84(1.32$ to 2.55$)$ & $1.02(0.69$ to 1.49$)$ \\
\hline Afro-Caribbean & 764 & 7.3 & $2.21(1.59$ to 3.07$)$ & 1.73 (1.23 to 2.42$)$ & $0.93(0.64$ to 1.36$)$ \\
\hline Indian subcontinent & 2178 & 5.7 & $1.64(1.17$ to 2.31$)$ & $1.64(1.11$ to 2.41$)$ & $1.05(0.72$ to 1.54$)$ \\
\hline Other groups & 787 & 5.9 & 1.75 (1.22 to 2.52$)$ & $1.64(1.22$ to 2.20$)$ & $0.98(0.62$ to 1.55$)$ \\
\hline
\end{tabular}

*As the English and Scottish representative samples include only a small number of children from ethnic minorities only the inner city sample was divided into four ethnic groups.

†The models were adjusted for child's sex and age, number of children in the family, parental atopy and maternal home smoking. The variables sample and ethnic group are also adjusted for social class or the Townsend score as appropriate. 




Figure 2 Odds ratio and 95\% confidence intervals of asthma attacks by area and Townsend scores in quartiles $(n=15495)$.

from the baseline area. A similar pattern was observed for the other respiratory symptoms (not shown).

\section{Discussion}

Based on three large samples in England and Scotland we have shown that there is considerable variation in the prevalence of persistent wheeze and other respiratory symptoms, except occasional wheeze and asthma, by level of poverty, father's social class, ethnic background, and geographical area. Adjusting for the Townsend score almost entirely eliminated the variation in persistent wheeze between ethnic groups. There was no geographical heterogeneity or social gradients for occasional wheeze, and asthma attacks were more frequent in the English representative sample than in the Scottish or inner city samples.

The strengths of this study are the very large sample size, the high response rate, the lack of bias related to samples relying on health service settings, and the participation of a large sample from most sectors of society. The weaknesses of the study are the possible variation in symptom reporting which is common to all studies relying on patients' or parents' reports.

Studies to date have concentrated on describing socioeconomic gradients or, in a few cases, assessing geographical variations in asthma prevalence within a country. We do not know of any community study that has shown geographical and socioeconomic gradients in the same analysis. Kaur and colleagues recently showed only minor geographical variation measured at regional or country level. ${ }^{13} \mathrm{Re}-$ gional variation may be too insensitive to socioeconomic variation between children.

Our results are compatible with the interpretation that socioeconomic gradients are associated mainly with the more severe forms of asthma (persistent wheeze). We did not have any further information on respiratory symptoms such as speech limiting breathlessness to explore this further. In four other community studies, in which a different definition of asthma severity was used, the authors also reached the conclusion that more severe forms of asthma are related to poverty. ${ }^{10111718}$ With the exception of an early Australian study which failed to show a gradient according to severity, ${ }^{19}$ the few other studies which have examined this issue are in agreement. This is in contrast to the findings of the large number of studies which have only looked at total asthma by socioeconomic status. ${ }^{10}$

In agreement with Strachan and colleagues, ${ }^{11}$ but not Kaur and colleagues, ${ }^{13}$ we found that asthma symptoms were less frequent in Scotland than in England. We also found that the prevalence of persistent wheeze in the Scottish sample was similar to that in the English representative sample, but the OR was substantially lower in Scotland than in England after adjustment for the Townsend score. This would indicate that, at the same level of wealth, Scottish children have less severe wheeze than English children. The reasons for the difference in our findings and those of Kaur and colleagues ${ }^{13}$ may be the differences in the ages of the subjects and in the methodology for obtaining information. Large differences in the prevalence of symptoms between the two studies, with much higher prevalences in the ISAAC UK study, suggest that differences in methodology are likely to be responsible.

The finding that symptoms suggestive of more severe forms of asthma are related to poverty is in agreement with reports that asthma mortality and admissions to hospital are associated with poverty. Although there are inconsistencies in detail, ${ }^{3820}$ most of the evidence points to poverty being implicated in asthma mortality ${ }^{3}$ and admissions to hospital. $^{2} 52122$

Perhaps the most powerful demonstration of the importance of poverty in the variation of severe asthma in the community was that adjustment for the Townsend score almost completely eliminated differences in persistent wheeze between the English representative sample and the inner city sample. This has not 




Figure 3 Odds ratio and 95\% confidence intervals of persistent wheeze by area and Townsend scores adjusted for age, sex, parents' clinical atopy, maternal smoking at home, number of children in the family, and father's social class $(n=15495)$.

been shown by other researchers before. Although others have analysed geographical variation, the unit of observation has been too large for informative analysis. ${ }^{11}{ }^{13}$ We also showed considerable variation in persistent wheeze related to father's social class, but adjustment for social class did not eliminate differences between symptoms by sample. This may be due to the low response rate to the question on father's occupation in a society in which a large percentage are mother headed one parent families and in which many parents do not wish to disclose their occupation. We had sufficient information to classify children by father's social class in approximately $75 \%$ of those in the Scottish and English samples, but only in $44 \%$ of those in the inner city sample. In contrast, the Townsend score can be applied to all children.

The geographical variation in persistent wheeze may be due to poverty itself or to poor management of asthma in poorer areas. In an earlier analysis we found that only $20 \%$ of children with persistent wheeze, but not asthma attacks, were receiving bronchodilators and only $5 \%$ were receiving anti-inflammatory drugs. ${ }^{24}$ This contrasted with at least $80 \%$ of children with asthma attacks receiving bronchodilators and $25 \%$ receiving antiinflammatory drugs. Other studies, ${ }^{25}{ }^{26}$ but not all research on community based samples, ${ }^{11}$ have shown the same association. Poor management of asthma in patients from a poor background is a recurrent theme in the literature. Explanations for this association include general practice characteristics, ${ }^{27}$ poor access to health facilities, ${ }^{4}$ patients' characteristics, ${ }^{28}$ and patients bypassing general practice and attending $\mathrm{A} \& \mathrm{E}$ departments. ${ }^{5}$ As our study is a community survey of symptoms, only general practice characteristics and patients' beliefs regarding asthma treatment may explain low rates of appropriate management of children with persistent wheeze in poor areas. In a population with such a diversity of cultural background research on patients' beliefs associated with asthma treatment could be rewarding. ${ }^{29}$ In our results ethnic differences in persistent wheeze were highly significant and tended to disappear after adjustment for the Townsend score. This would suggest that poverty may explain, to a great extent, the differences in persistent wheeze between ethnic groups.

An alternative explanation is that material and behavioural characteristics associated with poverty, other than adherence to treatment, may affect the prevalence of persistent wheeze. Parental smoking, indoor and outdoor air pollution, housing conditions, and allergens have all been found to exacerbate wheeze. In our study we adjusted for maternal smoking and its effect on geographical variability of persistent wheeze was minimal. We did not collect data on air pollution and housing characteristics, but the extent to which these two factors are associated with severe asthma is controversial. In the USA high asthma morbidity in inner city children has been related to cockroach allergen. ${ }^{30}$ However, in Britain the percentage of children positive to cockroach allergen in an inner city was substantially lower than in the USA. $^{31}$

In conclusion, this study strongly suggests that persistent wheeze, but not all symptoms of asthma, is associated with geographical variation which is largely explained by variation in deprivation. Ascertaining what factors associated with poverty can cause an increase in the prevalence of persistent wheeze may provide clues for effectively tackling the increasing number of children with asthma attending A\&E departments and admitted to hospital from poor sectors of the community.

The authors thank colleagues in the team, parents, children, and helpers. The study was funded by the Department of Health and Scottish Home and Health Department.

1 Ayres JG. Acute asthma in Asian patients: hospital admissions and duration of stay in a district with a high immigrant population. Br f Dis Chest 1986;80:242-8. 
2 Carr W, Zeitel L, Weiss K. Variations in asthma hospitalizations and deaths in New York City Am 7 Public Health tions and deaths

3 Higgins BG, Britton JR. Geographical and social class effects on asthma mortality in England and Wales. Respir Med 1995;89:341-6.

4 Jones AP, Bentham G. Health services accessibility and deaths from asthma in 401 local authority district in England and Wales, 1988-92. Thorax 1997;52:218-22.

5 Watson JP, Cowen P, Lewis RA. The relation between asthma admission rates, routes of admission, socioeconomic deprivation. Eur Respir f 1996;9:2087-93.

6 Weiss KB, Wagener DK. Geographic variations in US asthma mortality: small area analysis of excess mortality, 1981-1985. Am f Epidemiol 1990;132:S107-13.

7 Wissow LS, Gittelsohn AM, Szklo M, et al. Poverty, race, and hospitalization for childhood asthma. Am f Public Health 1988;78:777-82.

8 Charlton JRH, Hartley RM, Silver R, et al. Geographical variation in mortality from conditions amenable to variation in mortality from conditions amenable to medical in

9 Pattemore PK, Asher MI, Harrison AC, et al. Ethnic differences in prevalence of asthma symptoms and bronchial hyperresponsiveness in New Zealand schoolchildren. Tho$\operatorname{rax} 1989 ; 44: 168-76$

10 Mielck A, Reitmeir P, Wjst M. Severity of childhood asthma by socioeconomic status. Int $\mathcal{F}$ Epidemiol 1996;25:388-93.

11 Strachan DP, Anderson HR, Limb ES, et al. A national survey of asthma prevalence, severity, and treatment in Great Britain. Arch Dis Child 1994;70:174-8.

12 Strachan DP, Golding J, Anderson HR. Regional variation in wheezing illness in British children: effect of migration during early childhood 7 Epidemiol Community Health 1990;44:231-6.

13 Kaur B, Anderson HR, Austin J, et al. Prevalence of asthma symptoms, diagnosis, and treatment in 12-14 year old children accross Great Britain (International Study of Asthma and Allergies in Childhood, ISAAC UK). BMF 1998;316: and Allergi 118 .

14 Rona RJ, Altman DG. National Study of Health and Growth: standards of attained height, weight and triceps skinfold in English 5 to 11 years old. Ann Hum Biol 1977; 4:501-23.

15 Osborn AF, Butler NR, Morris AC. The social life of Britain's five year olds. A report of the Child Health and Education Study. London: Routledge and Kegan Paul, 1984.

16 Rona RJ, Chinn S. National Study of Health and Growth: social and biological factors associated with height of children from ethnic minorities living in England. Ann Hum Biol 1986;13:453-71.
17 Townsend P, Phillimore P, Beattie A. Health and deprivation: inequalities and the North. London: Routledge (Croom Helm), 1988

18 Littlejohns P, Macdonald LD. The relationship between severe asthma and social class. Respir Med 1993;87:139-43.

19 McNichol KN, William HE, Allan J, et al. Spectrum of asthma in children. III. Psychological and social components. BMf 1973;4:16-20.

20 Erzen D, Carriere KC, Dik N, et al. Income level and asthma prevalence and care patterns. Am $\mathcal{F}$ Respir Crit Care Med 1997;155:1060-5.

21 Wissow LS, Gittelsohn AM, Szklo M, et al. Poverty, race, and hospitalization for childhood asthma. Am $\mathcal{f}$ Public Health 1988;78:777-82.

22 De Palo VA, Mayo PH, Friedman P, et al. Demographic influences in asthma admission rates in New York City. Chest 1994;106:447-51.

23 Strachan DP, Golding J, Anderson HR. Regional variations in wheezing illness in British children: effect of migration in wheezing illness in British children: effect of migration during early child

24 Duran-Tauleria E, Rona RJ, Chinn S, et al. Influence of ethnic group on asthma treatment in children in 1990-1: national cross-sectional study. BMF 1996;313:148-52.

25 Anderson HR, Bailey PA, Cooper JS, et al. Influence of morbidity, illness, label, and social, family, and health service factors on drug treatment of childhood asthma. Lancet 1981;ii:1031-2.

26 Mitchell EA, Stewart AW, Pattemore PK, et al. Socioeconomic status in childhood asthma. Int 7 Epidemiol 1989;18: $888-90$

27 Griffiths C, Sturdy P, Naish J, et al. Hospital admissions for asthma in east London: association with characteristics of local general practices, prescribing, and population. BMf 1997;314:482-6.

28 Morgan M, Olding B. Patients beliefs and asthma treatment: extending the traditional compliance framework. Thorax 1995:50(Suppl 2):A53.

29 Wade S, Weil C, Holden G, et al. Psychosocial characteristics of inner-city children with asthma: a description of the NCICAS psychosocial protocol. Pediatr Pulmonol 1997;24: 263-76.

30 Rosenstreich DL, Eggleston O, Kattan M, et al. The role of cockroach allergy and exposure to cockroach allergen in causing morbidity among inner-city children with asthma. N Engl f Med 1997;336:1356-63.

31 Luczynska CM, Walker LA, Burney PGJ. Skin sensitivity in school children in two different areas of London. Eur Respir f 1995;8(Suppl 19):350S. 